\title{
Kuroshio Inferred from SSTs
}

\author{
Kern E. Kenyon \\ 4632 North Lane, Del Mar, USA
}

Correspondence to: Kern E. Kenyon, kernken@aol.com

Keywords: Kuroshio, SSTs

Received: October 31, $2018 \quad$ Accepted: November 26, $2018 \quad$ Published: November 29, 2018

Copyright $\odot 2018$ by author and Scientific Research Publishing Inc.

This work is licensed under the Creative Commons Attribution International License (CC BY 4.0).

http://creativecommons.org/licenses/by/4.0/

\section{c) (i) Open Access}

\section{ABSTRACT}

Twenty years of ship-injection temperatures are averaged annually and plotted against longitude in the western tropics of the North Pacific. Centered at $150 \mathrm{E}$ at both $20 \mathrm{~N}$ and $25 \mathrm{~N}$ is a large-scale longitudinal maximum in sea surface temperature. The simplest interpretation of this permanent feature is that a continuous flow of warm surface water out of the south is required to maintain it, since some heat will escape into the atmosphere in transit. It is concluded that the northward flow is the Kuroshio.

\section{INTRODUCTION}

There exists a comprehensive introduction for initiating study of the Kuroshio [1]. Unfortunately the present examination, as well as an earlier one [2], does not intersect with it in any meaningful way, as far as I can determine. Two reasons are that the interpretation given below is based on an extensive but unpublished SST data set, and the earlier discussion involved the BT atlas of the North Pacific by Margret Robinson, which was published four years after the introduction [1] was. According to the rhetoric of the introduction, one expects to find the Kuroshio to be quite similar to the Gulf Stream, which in particular has a very narrow width. Such a similarity does not show up in the classical world atlas of sea surface temperatures (H. O. 225), and no support for this concept is found below either. Although the temperature contours in H. O. 225 off the southern east coast of the US do show a thin (about one degree of longitude) finger of warm water pointing northeast in all monthly mean charts, there is no such analogous feature visible in the isotherms off Japan in that atlas.

\section{NAMIAS-SCRIPPS SST DATA SET}

Millions of individual ship-injection temperatures are incorporated into the Namias-Scripps data set, formatted as monthly means for all five degree latitude/longitude squares of the North Pacific at and north of $20 \mathrm{~N}$. In my possession are 30 years of these data starting with 1947, and twenty year averages for each month and location had also been provided. In the 1970s I had analyzed these data for the mid-latitude region adjacent to California resulting in the prediction of a wide (about $4000 \mathrm{~km}$ at $35 \mathrm{~N}$ ) warm surface current heading northeast [3]. Subsequent accumulation of existing data plus undertaking a complete hy- 
drographic section from California to Japan in March/April 1976 led to obtaining the depth scale of about $100 \mathrm{~m}$ for the current and an estimate for the mean flow speed in the range $10-20 \mathrm{~m} / \mathrm{sec}$.

A signature feature of the mid-latitude SSTs is that if one moves due west, it will be found that the surface temperature gradually rises to a maximum and then falls off again. Over the 30 year period of the ship-injection temperatures the longitudinal maximum exists for $35 \mathrm{~N}$ and $40 \mathrm{~N}$ in all monthly means, which qualifies the feature to be classified as permanent. Enough independent checks on these data have been done, using more accurate thermometers and more closely spaced readings, to qualify the feature as being real as well. Logic suggests that the most likely way to sustain the maximum is to continually bring to the region warmer water from the south or southwest, since some heat will undoubtedly leak out into the atmosphere in transit. Thus the concept of a wide warm surface current flowing northeast off California came to mind, and was published after ten years of work [3].

This wide warm current off California has no name yet, but the same reasoning can be applied to a current that is well known: the Kuroshio. Evidently that has not been done before, which provides the topic coming up next. It stands to reason that if the Kuroshio can be as narrow as the Gulf Stream, approaching one degree of longitude according to H. O. 225, then the Namias-Scripps network of five degree latitude/longitude squares would never capture it. Fortunately that turns out not to be the case.

\section{KUROSHIO AND SSTS}

Water temperature and the Kuroshio have been coupled together recently [2] through the mixed layer depth data in the BT atlas of the North Pacific, organized by Margaret Robinson. There is a trough of deep mixed layers off the east coast of Japan within which the waters are relatively warm and nearly uniform vertically. This trough exists in all twelve monthly mean charts as illustrated by contours of mixed layer depths in the atlas. Centerline curves, continuously connecting the deepest depths of the mixed layers, have been displayed [2] and they locate the approximate mid-points of the trough. It is presumed that the relatively warm water moves northeast in the trough off Japan, and cooling from above produces the deep mixed layers by penetrative convection. In conclusion, the trough is thought to be a signature feature of the Kuroshio.

As a next step, sea surface temperatures are related to the Kuroshio starting with Figures 1-3. All

Sea Surface Temperatures

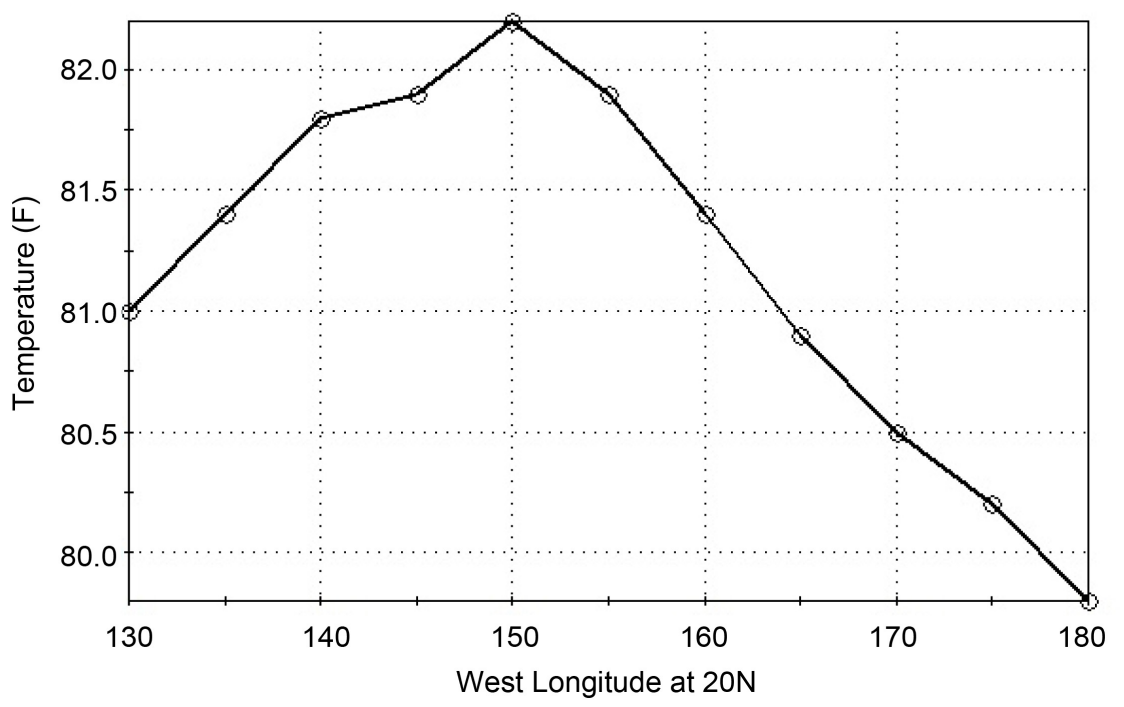

Figure 1.20 year mean annually averaged SSTs against longitude at $20 \mathrm{~N}$. 


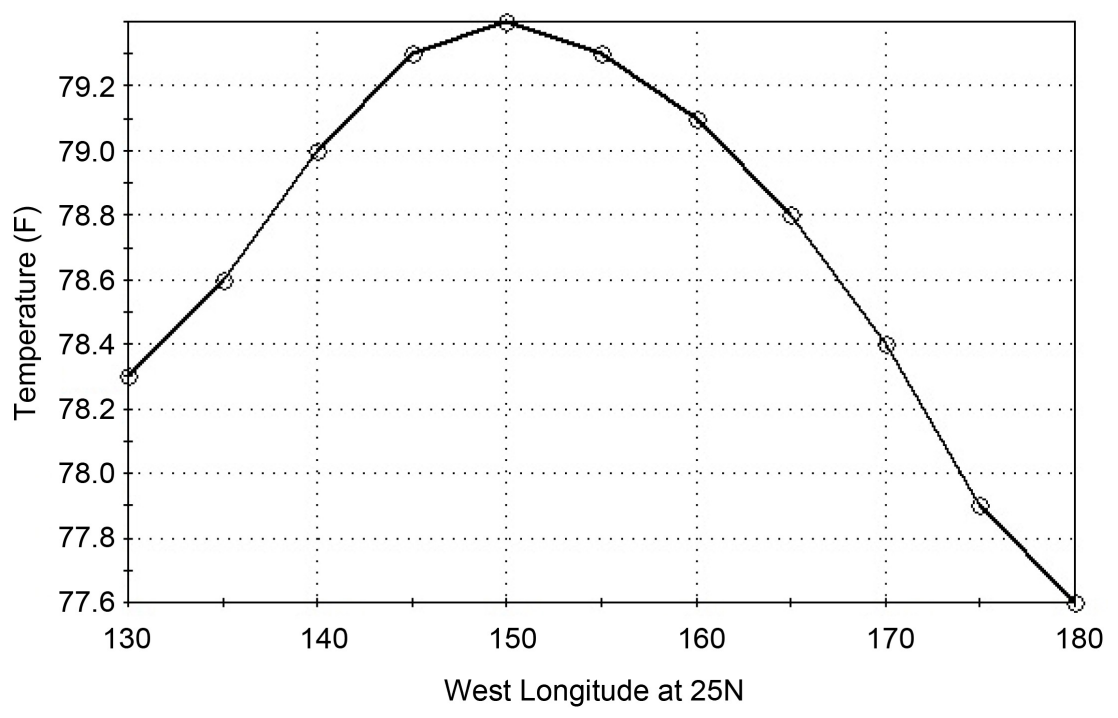

Figure 2. Same as Figure 1 except $25 \mathrm{~N}$.

Sea Surface Temperatures

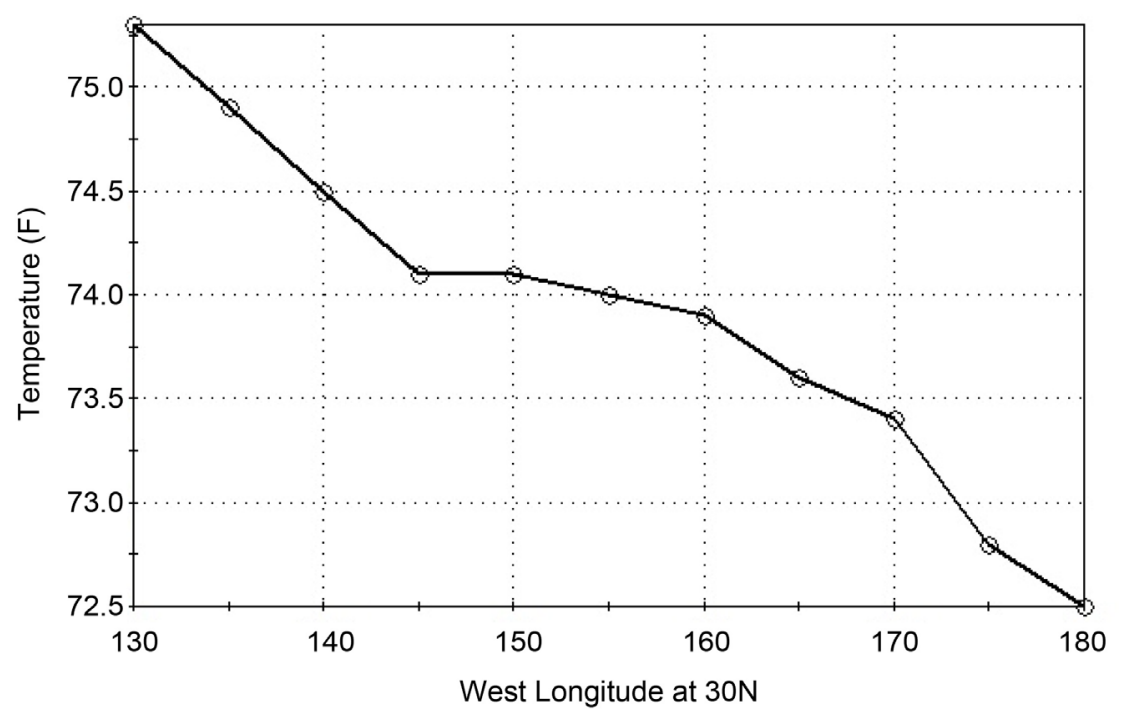

Figure 3. Same as Figure 1 and Figure 2 except 30N.

three figures show twenty year averaged sea surface temperatures plotted against longitude for the western tropics of the North Pacific, taken from the Namias-Scripps data set. In Figure 1 and Figure 2 there is clear evidence of a large scale longitudinal SST maximum centered at $150 \mathrm{E}$ along both $20 \mathrm{~N}$ and $25 \mathrm{~N}$. Since the shapes of this maximum are very similar for each of the twelve months, the temperatures just going up and down seasonally, there was no need to display all these individual curves. Therefore each characteristic curve is an average over all months.

Here comes the reasoning. In order to sustain the permanent longitudinal SST maximum in Figure 1 and Figure 2, warmer water has to continually be brought into the region from the south, because some heat will undoubtedly be lost to the atmosphere during the process. Thus a northward surface current 
centered at around $150 \mathrm{E}$ is proposed. It can only be the Kuroshio.

\section{DISCUSSION}

What about Figure 3 that has no distinct maximum along $30 \mathrm{~N}$, perhaps just a faint hint of one? When the flow heads mostly north, that is when a longitudinal SST maximum is expected. Somewhere between $25 \mathrm{~N}$ and $30 \mathrm{~N}$ the centerline curves of the deep mixed layer troughs make a sharp right turn to head more easterly, and this happens for all twelve monthly means [2]. Thus the flow itself is believed to do the same thing: head more east than north in this area.

Also the hydrographic section from California to Japan in April of 1976 is interpreted to have sliced directly through the meandering current while approaching Japan along 35N [2]. More than 500 XBTs dropped every $20 \mathrm{~km}$ along that cruise track gave a definitive picture of the temperature structure in the upper $500 \mathrm{~m}$ of the water column. Independently the centerline curve for April is one of the few to exhibit a meander pattern near $35 \mathrm{~N}$.

\section{CONFLICTS OF INTEREST}

The authors declare no conflicts of interest regarding the publication of this paper.

\section{REFERENCES}

1. Stommel, H. and Yoshida, K., Eds. (1972) Kuroshio: Physical Aspects of the Japan Current. University of Washington Press, Seattle.

2. Kenyon, K.E. (2018) Japan's Deep Mixed Layer Trough: Kuroshio? European International Journal of Science and Technology, Vol. 7, No. 7.

3. Kenyon, K.E. (1981) A Shallow Northeastward Current in the North Pacific. Journal of Geophysical Research, 86, 6529-6536. https://doi.org/10.1029/JC086iC07p06529 